\title{
Surface reactivity of Ag-modified ceria to hydrogen: a combined experimental and theoretical investigation
}

\author{
Stefania Benedetti ${ }^{1}$, Giulia Righi ${ }^{1,2, \#}$, Paola Luches ${ }^{1}$, Sergio D'Addato ${ }^{1,2}$, Rita Magri ${ }^{1,2, *}$, Annabella \\ Selloni ${ }^{3}$
}

${ }^{1} \mathrm{CNR}$ - Instituto Nanoscienze, via Campi 213/A, 41125 Modena, Italy

${ }^{2}$ Dipartimento di Fisica, Informatica e Matematica, Università di Modena e Reggio-Emilia, via Campi 213/A, 41125 Modena, Italy

${ }^{3}$ Department of Chemistry, Princeton University, New Jersey, 08540, United States

Keywords: ceria, metal dopants, hydrogen dissociation, X-ray photoemission spectroscopy, density functional theory, reaction kinetics, surface reduction, silver

\begin{abstract}
We investigate the mechanism of $\mathrm{H}_{2}$ activation on Ag-modified cerium oxide surfaces, of interest for different catalytic applications. The study is performed on thin epitaxial cerium oxide films, investigated by X-ray photoemission spectroscopy to assess the changes of both the Ag oxidation state and the concentration of $\mathrm{Ce}^{3+}$ ions, $\mathrm{O}$ vacancies and hydroxyl groups on the surface during thermal reduction cycles in vacuum and under hydrogen exposure. The results are interpreted using density functional theory calculations to model pristine and $\mathrm{Ag}$-modified ceria surfaces. Although the reactivity of ceria towards $\mathrm{H}_{2}$ oxidation improves when a fraction of Ce cations is substituted with $\mathrm{Ag}$, the concentration of reduced $\mathrm{Ce}^{3+}$ ions in $\mathrm{Ag}$-modified ceria is found to be lower than in pure ceria under the same conditions. This behavior is observed even though the number of surface oxygen vacancies caused by the thermal treatment under hydrogen exposure is larger for the Ag-modified surface. These results are explained in terms of a change of the oxidation state of the surface $\mathrm{Ag}$, which is able to acquire some of the extra surface electrons created by the oxygen vacancies and the adsorbed hydrogen atoms. Our findings provide new insights into the reactivity of Ag-modified ceria, which has been proposed as a promising alternative to platinum electrodes in electro-chemical devices.
\end{abstract}

\section{Introduction}

Recently, a wealth of research efforts has been devoted to the search of earth-abundant electrode materials that might replace platinum, the best-known catalyst currently employed in industrial applications. Among such materials reducible metal oxides have been found to have a high potential for many different applications, and, in particular, for catalytic reactions in electrochemical devices ${ }^{1}$. 
Reducible oxides play an important role in heterogeneous catalysis due to their ability to store or release oxygen depending on the conditions of pressure and temperature. ${ }^{23} \mathrm{Among}$ reducible oxides, $\mathrm{CeO}_{2}$ has been suggested for a number of applications, from biomedicine ${ }^{4}$ to fuel cells $(F C)^{5}{ }^{6}$. For example, motivated by the need to decrease the amount of Pt used in electrochemical devices, numerous studies have shown that Pt-modified $\mathrm{CeO}_{2}$ is a promising electrode material for proton-exchange membrane FCs (PEMFCs), due to its high activity in mediating the formation of protons from gas-phase $\mathrm{H}_{2}^{6}$. In this context, it has been proposed that single atom catalysts can provide a viable route to further decrease the concentration of noble metal on the oxide surface ${ }^{7}$.

Ceria-based catalysts are of considerable interest also for hydrogenation reactions ${ }^{89}$. Cerium oxide powder catalysts have been shown to be active towards $\mathrm{H}_{2}$ dissociation, with an activity that depends on variables like the size and morphology of the catalysts and the density of defects and oxygen vacancies ${ }^{10}$. On the other hand, studies on model (111) ceria surfaces show that high temperatures and/or high pressures are required to dissociate $\mathrm{H}_{2}{ }^{11}{ }^{12}$. On such surfaces the presence of oxygen vacancies favors $\mathrm{H}$ migration into the bulk ${ }^{12}$, and temperature influences the steps that bring from $\mathrm{H}$ adsorption to ceria reduction. ${ }^{13}$

It is known that cation doping often improves the catalytic activity of metal oxides ${ }^{13}$. In ceria, cation dopants usually sit at substitutional cerium sites ${ }^{14}{ }^{15}$. In particular, Ag constitutes a low-valence dopant (LVD) in $\mathrm{CeO}_{2}$ since in its stable oxides it has a lower valence than the $\mathrm{Ce}$ atoms in $\mathrm{CeO}_{2}$. An interesting feature of LVD dopants is to make the neighboring oxygen atoms much more reactive ${ }^{13}$. Density functional theory (DFT) calculations on $\mathrm{Ag}$ single atoms on the $\mathrm{CeO}_{2}(111)$ surface have indeed found that one oxygen in proximity of the $\mathrm{Ag}$ dopant can spontaneously leave the surface in an exothermic reaction ${ }^{16}{ }^{17}$. Since oxygen vacancies induce excess electrons that can reduce the oxidation state of $\mathrm{Ce}$ from $4+$ to $3+$ (with the extra electron occupying the localized $f$ orbital), it is expected that the presence of Ag will ultimately lead to the creation of additional reduced cerium atoms on the $\mathrm{CeO}_{2}$ surface ${ }^{18} 19$.

More generally, experiments and calculations on ceria deposited on transition and noble metal supports or, vice versa, on metal nanoparticles deposited on a ceria support, have shown an increase of $\mathrm{Ce}^{3+}$ concentration as a consequence of the thin film/support interaction 19202122172324 . Also doping with metals such as $\mathrm{Cu}$ and Rh has been reported to enhance the oxide reducibility 252627282917 . Higher concentrations of $\mathrm{Ce}^{3+}$ cations are often considered to be linked to a higher reactivity of the film to $\mathrm{H}_{2}$ activation. In fact, DFT studies have shown that $\mathrm{H}_{2}$ dissociation on pristine ceria surfaces leads to the formation of surface hydroxyl groups and the reduction of $\mathrm{Ce}^{4+}$ to $\mathrm{Ce}^{3+}$ cations 30313233 . Moreover, a recent combined experimental and theoretical study found that isolated $\mathrm{Pt}^{2+}$ species on $\mathrm{CeO}_{2}$ are inactive due to the large activation energy for breaking the $\mathrm{H}-\mathrm{H}$ bond, and trace amounts of metallic Pt are necessary to initiate $\mathrm{H}_{2}$ dissociation; this leads to the reduction of $\mathrm{Ce}^{4+}$ cations which, in turn, is coupled to the reduction of $\mathrm{Pt}^{2+}$ species. ${ }^{34} \mathrm{As}$ a result of these and 
related studies, one of the experimental approaches for the study of $\mathrm{H}_{2}$ dissociation on metal doped ceria films is to determine the oxidation states of both the dopant metal cation and the Ce cations using photoemission spectroscopy ${ }^{34}$.

In the present study we provide new insights into the mechanisms of $\mathrm{H}_{2}$ dissociation on $\mathrm{Ag}$-modified ceria, with the aim to elucidate the role of $\mathrm{Ag}$ in the surface reactivity and its relation to the reduction of the $\mathrm{Ce}^{4+}$ cations. We will discuss in particular the validity of assessing the reactivity of the surface towards $\mathrm{H}_{2}$ dissociation by monitoring the concentration of the $\mathrm{Ce}^{3+}$ reduced cations.

\section{Methodology}

\section{Experiment}

$\mathrm{CeO}_{2}$ films were grown on $\mathrm{Pt}(111)$ single crystals, prepared by repeated cycles of Ar sputtering (1 keV, $\left.1 \mu \mathrm{A} / \mathrm{cm}^{2}\right)$ and annealing $(1040 \mathrm{~K})$. The clean surface showed no impurities within the $\mathrm{X}$-ray photoelectron spectroscopy (XPS) detection limit and a sharp $(1 \times 1)$ low energy electron diffraction pattern. $\mathrm{CeO}_{2}$ films were grown by e-beam evaporation of $\mathrm{Ce}$ atoms in $\mathrm{O}_{2}$ partial pressure of $1 \times 10^{-7} \mathrm{mbar}$ introduced through a nozzle. During the evaporation the substrate was kept at room temperature (RT). An evaporation rate of $0.4 \AA$ was measured with a quartz microbalance before evaporation and the film thickness was checked by XPS after deposition. A film thickness of $1.5 \mathrm{~nm}$ corresponding to $5 \mathrm{ML}$ was chosen. Ag-modified $\left(\mathrm{Ag}: \mathrm{CeO}_{2}\right)$ films of the same thickness were obtained by co-deposition of Ag atoms by an effusion cell pointing towards the same position as the e-beam Ce evaporator, where the sample is placed. After deposition the films were annealed at $770 \mathrm{~K}$ in $1 \times 10^{-7} \mathrm{mbar}_{2}$ partial pressure in order to improve crystalline order and obtain full oxidation of the film. An Ag concentration of 10 at\% was measured by XPS after the treatment.

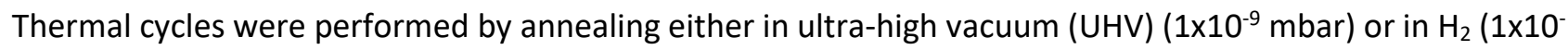
${ }^{7} \mathrm{mbar}, 99.9995 \%$ purity) for $15 \mathrm{~min}$ at four different temperatures: $470 \mathrm{~K}, 570 \mathrm{~K}, 670 \mathrm{~K}$ and $770 \mathrm{~K}$ and cooling to $\mathrm{RT}$ in reducing atmosphere ( $\mathrm{UHV}$ or $\mathrm{H}_{2}$ ). In UHV conditions the residual $\mathrm{H}_{2} \mathrm{O}$ partial pressure is $3 \times 10^{-10} \mathrm{mbar}$. When $\mathrm{H}_{2}$ is introduced in the chamber no change in $\mathrm{H}_{2} \mathrm{O}$ partial pressure is observed. The XPS measurements were performed in UHV conditions at RT after each reduction step, exploiting an AI-Ka X-ray source and a hemispherical analyzer (overall resolution $1 \mathrm{eV}$ ). The spectra were measured at grazing emission with respect to the sample surface ( $65^{\circ}$ off-normal). The Ce $3 \mathrm{~d}$ spectra were fit using five doublets - three related to $\mathrm{Ce}^{4+}$ ions and two related to $\mathrm{Ce}^{3+}$ ions -, following the procedure by Skala ${ }^{35} 36$ (see Supporting Information for details, Figure S1). The $\mathrm{Ce}^{3+}$ concentration is obtained from the fits by considering the ratio of the area of the two $\mathrm{Ce}^{3+}$ related doublets and the total area of the five doublets. The error on the concentration is estimated from the fits as $\pm 2 \%$. Indeed, the accuracy of the absolute values obtained is possibly lower, due to the complexity of the spectra and of the background. Moreover, the true $\mathrm{Ce}^{3+}$ surface concentration is probably 
systematically underestimated because of a partial sensitivity of XPS also to the deeper layers, which are not expected to be affected by reduction. However, the considerations made in this work are based only on the trends observed for the $\mathrm{Ce}^{3+}$ concentration with the temperature for the two different surfaces and in the two different environments and not on the absolute values of the concentration. The binding energy scale has been calibrated to have the Pt $4 \mathrm{f}$ peak at $71.2 \mathrm{eV}$. The $01 \mathrm{~s}$ spectra were fit by the sum of two Voigtshaped peaks with the same width, fixed binding energies, and using their intensities as a fitting parameter. The Ag 3d peaks were fit by a Doniach-Sunjich doublet to determine their binding energy.

Scanning tunneling microscopy (STM) was used to check for possible modifications of surface morphology induced by doping and/or by the thermal treatments. The STM images were acquired at RT with an Omicron RT AFM/STM using a W tip in constant current mode and with a positive sample-to-tip bias. The images were processed using WSxM software ${ }^{37}$.

\section{Density Functional Theory calculations}

We performed ab-initio spin-polarized calculations using the Perdew-Burke-Ernezhof (PBE) ${ }^{38}$ exchange and correlation functional as implemented in the Quantum Espresso package ${ }^{39}{ }^{40}$. Ultrasoft pseudopotentials ${ }^{41}$ were employed to describe the interaction between electrons and ions. The wave function and charge density cutoff were set to 30 Ry and 240 Ry, respectively. To treat the strongly correlated electrons in the $f$ orbitals of $\mathrm{Ce}$ atoms we have used the Hubbard Correction (DFT+U), as implemented by Cococcioni. ${ }^{42}$. We have set the $\mathrm{U}$ value to $4 \mathrm{eV}$, as used previously ${ }^{16} 24$.

$\mathrm{CeO}_{2}$ crystallizes in the fluorite structure. Optimizing the primitive cell using a (7x7x7) Monkhorst-Pack ${ }^{43}$ grid we obtained an equilibrium lattice parameter $a=5.52 \AA$, in reasonable agreement with the experimental value, $a_{\text {exp }}=5.41 \AA^{44}$, and previous theoretical studies ${ }^{45} 46$.

To describe the surface, we used a (111) slab with a $(4 \times 4)$ surface supercell and three O-Ce-O trilayers. The periodically repeated slabs were separated by $15 \AA$ of vacuum. The positions of the atoms in the last trilayer were kept fixed to their bulk positions during the geometry optimization. The energy convergence threshold for the geometric optimizations was set to $10^{-5} \mathrm{eV}$. We relaxed the structure until the forces on the atoms of the slab were less than $0.01 \mathrm{eV} / \AA$. The Brillouin zone was sampled only at the Gamma point. The $\mathrm{O}_{2}$ molecule was relaxed in a box with a $20 \AA ̊$ edge.

We calculated the Oxygen vacancy formation energy $E_{\text {form }}$ as: $E_{f o r m}=E_{\text {def }}+1 / 2 E_{02}-E_{\text {pristine, }}$ where $E_{\text {def }}$ is the energy of the slab with one surface Oxygen vacancy, $E_{02}$ is the energy of the Oxygen molecule, and $E_{\text {pristine }}$ is the energy of the slab without the Oxygen vacancy. 

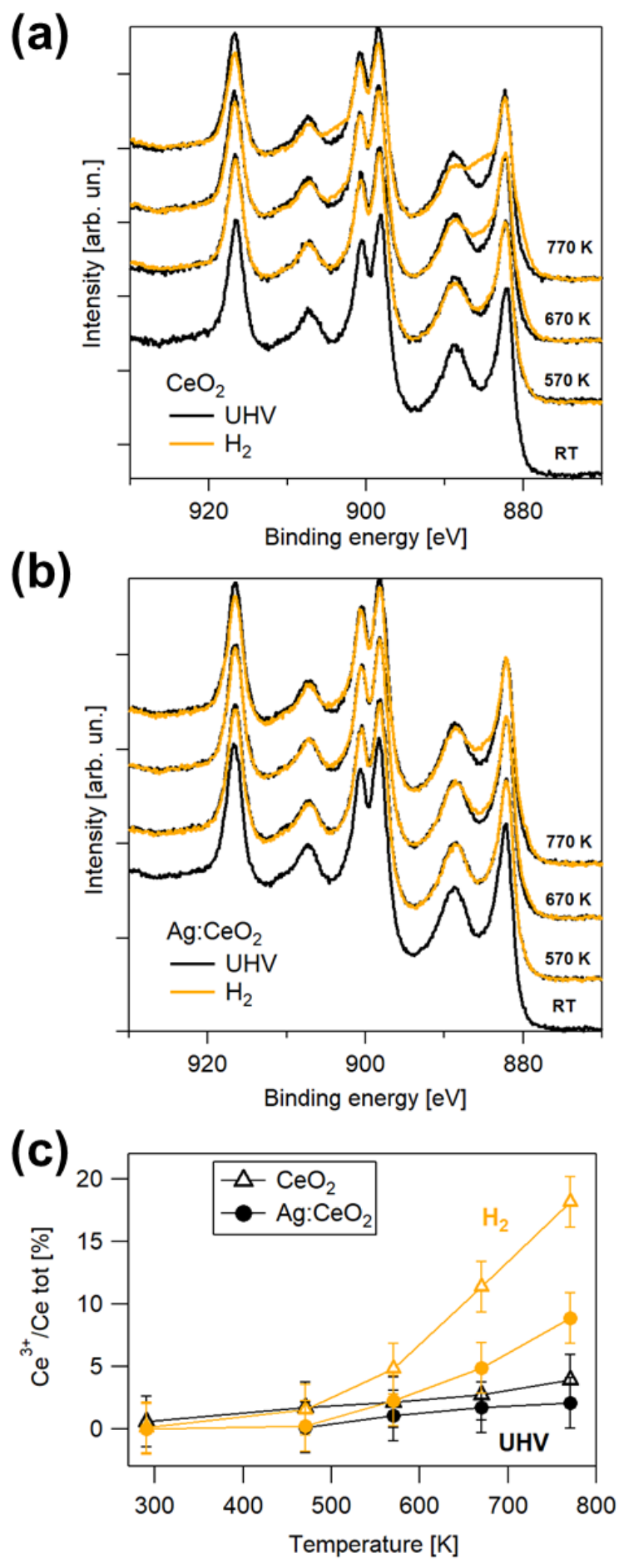

Figure 1. Ce 3d spectra for (a) pure and (b) Agmodified $\mathrm{CeO}_{2}$ film reduced at increasing temperature in UHV (black) and $\mathrm{H}_{2}$ partial pressure (orange). (c) $\mathrm{Ce}^{3+}$ concentration as a function of temperature for the different films and reducing conditions, obtained from the fit of the Ce $3 d$ spectra in panel (a) and (b).
To model the Ag-modified surfaces, we considered an $\mathrm{Ag}$ atom substituting one of the $\mathrm{Ce}$ atoms of the first monolayer, where the dopant effect on the surface reactivity is expected to be most important. This specific configuration is suggested by experimental results showing that noble metals such as $\mathrm{Au}$ and $\mathrm{Pt}$ tend to occupy cation positions ${ }^{14} 1547$. We focused on the (111) surface of ceria, which is the one exposed in our experiments, and, in particular, the stable surface with one oxygen vacancy near the Ag ion ${ }^{16}$.

To determine the minimum energy paths (MEP) of $\mathrm{H}_{2}$ dissociation on the $\mathrm{Ag}: \mathrm{CeO}_{2}$ surfaces we have used the climbing image nudged method (CI-NEB) ${ }^{48}$ with seven images. The obtained activation energies have been compared with the energy required to oxidize the $\mathrm{H}_{2}$ molecule on the pristine ceria surface calculated in previous works 324931 using the same methodology. Charge transfers were calculated using the Bader approach ${ }^{50}$.

\section{Results and Discussion \\ EXPERIMENT}

\section{- Evolution of $\mathrm{Ce}^{3+}$ concentration}

To understand the role of $\mathrm{Ag}$ atoms in $\mathrm{CeO}_{2}$ we have investigated the changes induced by thermal cycles in reducing environments in a $5 \mathrm{ML}$ pure $\mathrm{CeO}_{2}$ film and in a film of the same thickness with substitutional $\mathrm{Ag}$ atoms. During the thermal cycle the film was exposed to the reducing environment (either UHV or $\mathrm{H}_{2}$ ) both during the annealing and the cooling to RT. The evolution of the $\mathrm{Ce}^{3+}$ concentration and the surface modifications in the film have been investigated by means of XPS and STM. 
Figure 1a compares the $\mathrm{Ce} 3 \mathrm{~d}$ spectra of the pure $\mathrm{CeO}_{2}$ film after the temperature treatment in $\mathrm{H}_{2}$ and, for comparison, in UHV in order to rule out the possible effects coming from the residual gas in the chamber. At RT the lineshape is consistent with the presence of $\mathrm{Ce}^{4+}$ ions only. It can be observed that the increase of the annealing temperature induces negligible variations in the lineshape under UHV conditions, while the annealing and the subsequent cooling in $\mathrm{H}_{2}$ modifies more significantly the $\mathrm{Ce} 3 \mathrm{~d}$ spectra, which show a relevant contribution from $\mathrm{Ce}^{3+}$ ions above $670 \mathrm{~K}$. The observed reduction is less pronounced at normal emission, showing that the process occurs mainly at the surface (see Supporting Information, Figure S2).

When 10 at\% of $\mathrm{Ag}$ atoms are added to the oxide matrix the trend is the same and annealing in $\mathrm{H}_{2}$ induces a larger reduction as compared to UHV treatments above $670 \mathrm{~K}$ (Figure $1 \mathrm{~b}$ ). A fit of the Ce $3 \mathrm{~d}$ spectra was performed to quantify the concentration of $\mathrm{Ce}^{3+}$ and $\mathrm{Ce}^{4+}$ in the two samples under the different treatments. The fits of the curves are reported in the Supporting Information (Figure S3 and Table S1). Figure 1c shows the $\mathrm{Ce}^{3+}$ concentration as determined by the fit for the two samples after the different reducing steps in UHV and in $\mathrm{H}_{2}$. The UHV treatment brings to a maximum $\mathrm{Ce}^{3+}$ concentration of about $4 \%$ in pure $\mathrm{CeO}_{2}$ and $2 \%$ in $\mathrm{Ag}: \mathrm{CeO}_{2}$. Annealing in $\mathrm{H}_{2}$ induces a non-negligible reduction in the pure oxide already at $470 \mathrm{~K}$, while for $\mathrm{Ag}: \mathrm{CeO}_{2}$ the $\mathrm{Ce}^{3+}$ concentration starts to increase at $570 \mathrm{~K}$. In general, the $\mathrm{Ce}^{3+}$ concentration is larger in the presence of $\mathrm{H}_{2}$ and it is significantly higher for the pure (18\%) as compared to the $\mathrm{Ag}: \mathrm{CeO}_{2}(9 \%)$ film at 770 K.

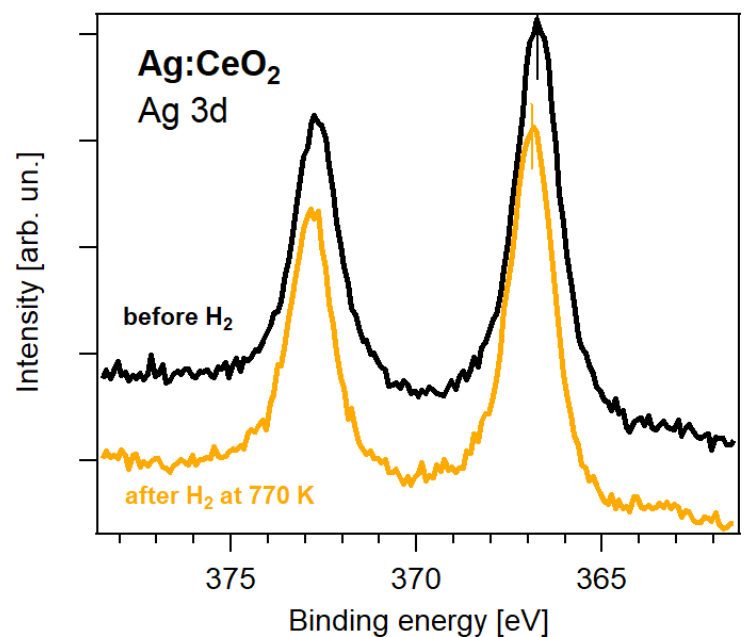

Figure 2: $\mathrm{Ag} 3 \mathrm{~d}$ peaks of the $\mathrm{Ag}$-modified $\mathrm{CeO}_{2}$ film before (black curve) and after (orange curve) $\mathrm{H}_{2}$ exposure at $770 \mathrm{~K}$.
The Ag 3d XPS lines were also measured at each step of the different thermal treatments in UHV and $\mathrm{H}_{2}$ for the $\mathrm{Ag}: \mathrm{CeO}_{2}$ sample (Figure 2). The spectra do not show any significant change in shape, width or intensity with the thermal treatments, showing a stable distribution of $\mathrm{Ag}$ in the matrix. A small binding energy shift is revealed after the film is treated in hydrogen. The Ag $3 d_{5 / 2}$ binding energy is $367.8 \mathrm{eV}$ before the $\mathrm{H}_{2}$ thermal treatment, while it shifts to $368.0 \mathrm{eV}$ afterwards. Ag $3 d_{5 / 2}$ in metallic silver has a binding energy of $368.2 \mathrm{eV}^{51}$, while it was shown that in its oxides an anomalous negative shift to lower binding energy occurs, because of extra-

atomic relaxation effects ${ }^{52}$. The data therefore show that $\mathrm{Ag}$ atoms in the ceria matrix are in an oxidized state and that the exposure to hydrogen partially reduces them, in accordance with theoretical predictions (see below). It is difficult to estimate the oxidation state from the absolute values of the binding energies. The value obtained before $\mathrm{H}_{2}$ reduction in fact corresponds to the literature one for $\mathrm{Ag}^{1+}$. However, previous 
studies have shown that the binding energies of metal cations in their bulk oxides can be different from those of the same cations with the same oxidation state introduced as low-concentration dopants in a matrix of a different oxide ${ }^{53}$.

\section{- Formation of surface oxygen vacancies and $\mathrm{OH}$ groups}

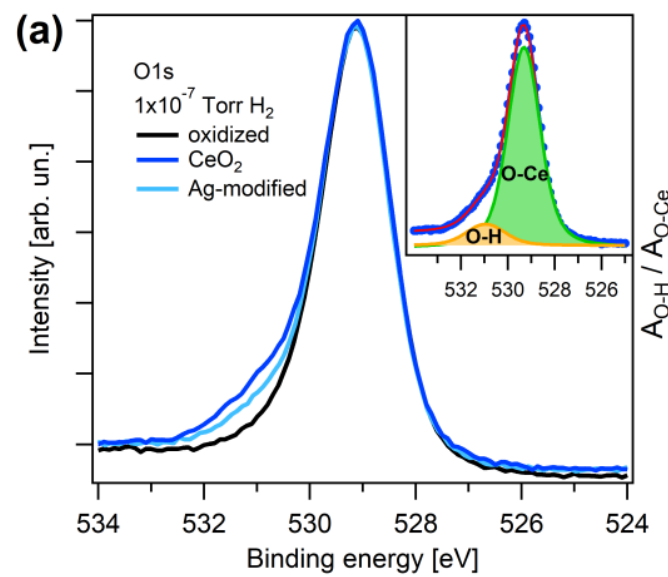

(b)

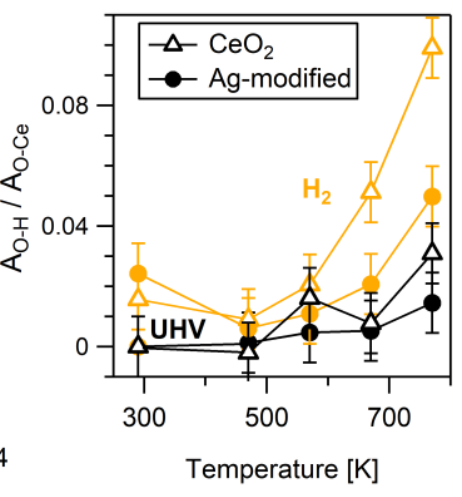

(c)

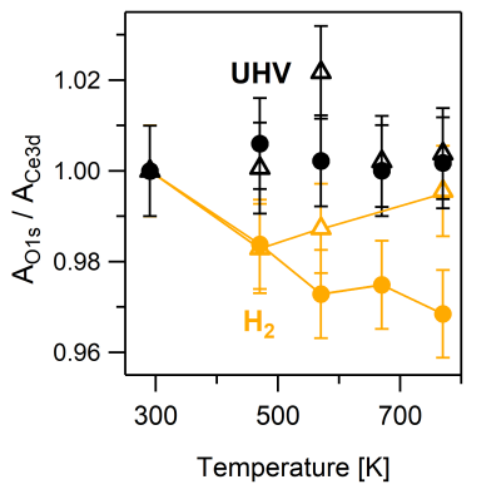

Figure 3. (a) $\mathrm{O} 1 \mathrm{~s}$ peaks of pure and $\mathrm{Ag}: \mathrm{CeO}_{2}$ films before and after exposure to $\mathrm{H}_{2}$ at $770 \mathrm{~K}$. Inset shows the Voigt peaks used for the fit of the pure $\mathrm{CeO}_{2}$ after exposure to $\mathrm{H}_{2}$. (b) Ratio between $\mathrm{H}$-coordinated $\mathrm{O}$ and Ce-coordinated $\mathrm{O}$ peaks after $\mathrm{H}_{2}$ (orange) and UHV (black) exposure (as obtained by the fit) as a function of temperature. (c) Ratio between $\mathrm{O} 1 \mathrm{~s}$ and $\mathrm{Ce} 3 \mathrm{~d}$ peak area after $\mathrm{H}_{2}$ exposure or UHV treatment at different temperatures.

During the thermal treatment in hydrogen, we also observed non-negligible modifications in the 01 s peak (Figure 3) in parallel to the modifications of the $\mathrm{Ce} 3 \mathrm{~d}$ peak. Increasing the temperature during $\mathrm{H}_{2}$ reduction a component appears at about $1.7 \mathrm{eV}$ higher binding energy with respect to the main peak (Fig. 3a). A quantitative estimation of the intensity of the new component is obtained through a fit with two Voigt peaks, a dominant one centered at $529.3 \mathrm{eV}$, assigned to $\mathrm{O}$ in cerium oxide lattice, and a small peak at $531 \mathrm{eV}$, related to $\mathrm{O}$ coordinated to $\mathrm{H}^{54}{ }^{55}$. An example of the resulting fit is reported in the inset of Figure $3 a$. Figure $3 \mathrm{~b}$ shows the ratio between the peaks of the $\mathrm{OH}$ component and the $\mathrm{O}-\mathrm{Ce}$ main component. The weight of the $\mathrm{OH}$ component is slightly higher for the $\mathrm{Ag}: \mathrm{CeO}_{2}$ film after $\mathrm{H}_{2}$ exposure at $\mathrm{RT}$, while it becomes significantly higher for the pure oxide after exposure at higher temperatures. The $\mathrm{OH}$-related intensity is higher at grazing emission than at normal emission, showing that the $\mathrm{OH}$ species are preferentially located at the surface (see Supporting Information, Figure S2).

The spectra of Figure 3a do not show any measurable peak at the binding energies where peaks from adsorbed water are expected, i.e. at approximately $533.5 \mathrm{eV}^{54556}$. Water does actually form, but it is released from the surface at high temperatures leaving $O$ vacancies. Moreover, the ceria surfaces reduced by thermal treatment in $\mathrm{H}_{2}$ have a low propensity towards adsorption of molecular water during their cooling to RT in hydrogen ${ }^{56}$. 
Figure $3 \mathrm{c}$ reports the ratio of the $\mathrm{O} 1 \mathrm{~s}$ to $\mathrm{Ce} 3 \mathrm{~d}$ areas after the different thermal treatment steps in $\mathrm{H}_{2}$ and UHV for the pure and the $\mathrm{Ag}: \mathrm{CeO}_{2}$ films. The ratio is approximately constant for both samples in UHV, in agreement with the negligible changes observed in the Ce $3 \mathrm{~d}$ lineshapes. In $\mathrm{H}_{2}$ environment, a more pronounced decrease of the ratio in the $\mathrm{Ag}: \mathrm{CeO}_{2}$ film as compared to the pure oxide film as a function of temperature is observed. This is related to the formation of a higher concentration of oxygen vacancies, and it can be very likely ascribed to a more efficient water formation on the Ag-modified surface.

\section{- Surface morphology}

To exclude possible contributions coming from differences in surface morphology or from uncovered substrate areas, we compare the STM images of the $\mathrm{CeO}_{2}$ film with and without Ag inclusion. Figure $4 a$ reports the STM image of the $\mathrm{CeO}_{2}$ film after the initial oxidation at $770 \mathrm{~K}$, showing that the film completely covers the Pt surface with grains of about $5 \mathrm{~nm}$ diameter. The morphology of the film with Ag inclusion is not significantly different from that of the pristine film (Figure 4b) and it is not modified after thermal treatments in $\mathrm{H}_{2}$ (see Supporting Information, Figure S4). Figure 4c shows two height profiles across the darkest areas observed on the film surfaces. For both films the average hole depth is about $1 \mathrm{~nm}$ (dashed line), well below the estimated film thickness of $1.56 \mathrm{~nm}(5 \mathrm{ML})$. The hole depth may be underestimated due to tip size effects, which have not been removed due to an unknown tip size. However, since the dark holes represent a very small surface fraction, similar for both pristine and $\mathrm{Ag}: \mathrm{CeO}_{2}$ surfaces, they are not expected to significantly influence the surface chemical activity observed so far.
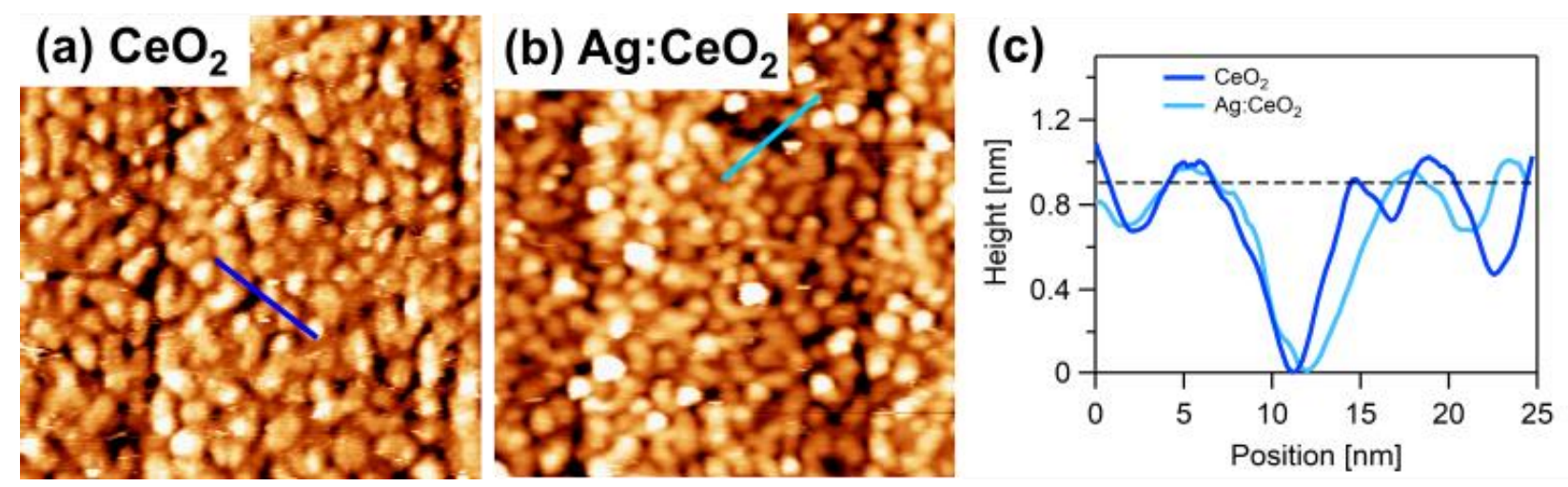

Figure 4. $100 \times 100 \mathrm{~nm}^{2} \mathrm{STM}$ images of $5 \mathrm{ML}(1.56 \mathrm{~nm})$ (a) pure $\mathrm{CeO}_{2}$ and (b) $\mathrm{Ag}: \mathrm{CeO}_{2}$ film, annealed at $770 \mathrm{~K}$ in $\mathrm{O}_{2}(\mathrm{U}=2.5 \mathrm{~V}, \mathrm{I}=0.08 \mathrm{nA})$. (c) Height profiles along the lines in images (a) and (b). 


\section{THEORY}

To obtain more detailed insight into our experimental observations, we further examined the reduction of the pristine and Ag-doped ceria surfaces under UHV conditions and in a $\mathrm{H}_{2}$ environment using DFT calculations. Side and top views of the pristine and $\mathrm{Ag}: \mathrm{CeO}_{2}(111)$ surface models investigated in this work are shown in Figure 5.

\section{- Reduction in vacuum}

Reducible oxides under UHV conditions tend to lose oxygen with increasing temperature. To characterize this process, we have calculated the energy required to create one oxygen vacancy $\left(\mathrm{O}_{v}\right)$ on the pristine and $\mathrm{Ag}: \mathrm{CeO}_{2}(111)$ surfaces. On pristine ceria (Figure $5 \mathrm{a}, \mathrm{b}$ ) the $\mathrm{O}_{\mathrm{v}}$ formation energy is $\mathrm{E}_{\text {form }}=2.02 \mathrm{eV}$, a value close to those reported in previous theoretical works ${ }^{57} 58$. Following the creation of the oxygen vacancy we observe the reduction of two Ce atoms on second neighbor sites of the $\mathrm{O}_{v}$.

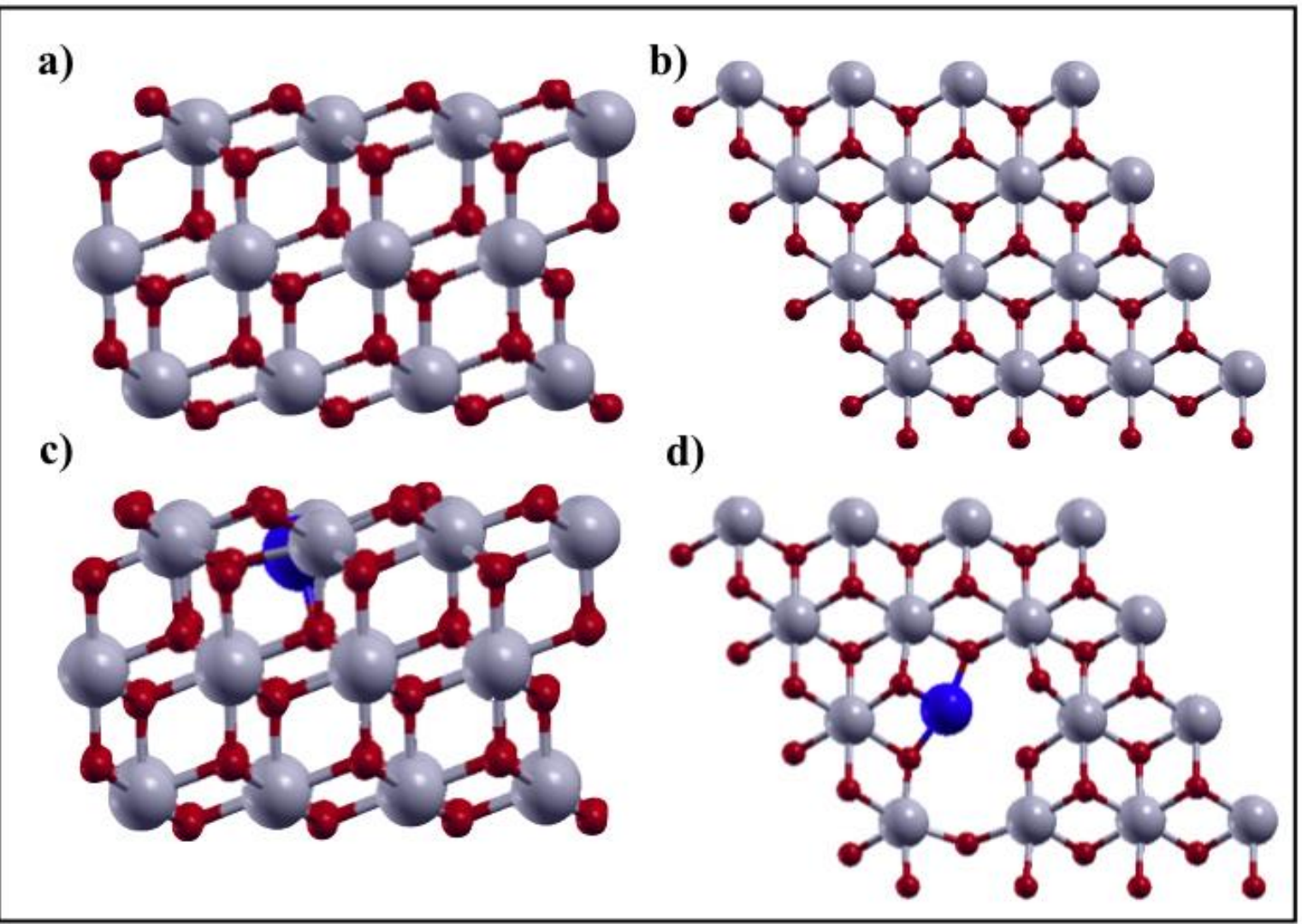

Figure 5. Side $(a, c)$ and top (b,d) views of the different surface configurations. a) and b) $\mathrm{CeO}_{2}$ surface; $c$ ) and d) $\mathrm{Ag}: \mathrm{CeO}_{2}$ surface. Gray, red and blue balls are the cerium, oxygen and silver atoms, respectively.

We modeled the $\mathrm{Ag}: \mathrm{CeO}_{2}$ surface by substituting one $\mathrm{Ce}$ atom per surface unit cell with $\mathrm{Ag}$. The oxygen ions near the Ag atom are less negatively charged than on the pristine ceria $(\approx-0.2 e)$, and are also more active 
than the other surface oxygen atoms ${ }^{59}$. The removal of one of such oxygens is a thermodynamically favored process with $\mathrm{E}_{\text {form }}=-0.76 \mathrm{eV}$. This implies that the most stable surface actually contains dopant-vacancy complexes, as shown in Figure $5 \mathrm{c}$ and $\mathrm{d}$. On this surface, the $\mathrm{Ag}$ oxidation state is $2+$, and the energy required to remove an additional oxygen atom close to $\mathrm{Ag}$ is positive, $0.78 \mathrm{eV}$, but still lower than on pristine $\mathrm{CeO}_{2}$. Creation of such an additional $\mathrm{O}_{v}$ reduces the $\mathrm{Ag}$ oxidation state from $2+$ to $1+$, while at the same time one surface $\mathrm{Ce}$ atom is reduced to $\mathrm{Ce}^{3+}$. Altogether, we can conclude that the formation of an oxygen vacancy on the Ag-modified surface causes the reduction of only one Ce atom, whereas two Ce atoms are reduced on the pristine surface. These results indicate that loss of surface oxygen due to thermal treatment under UHV conditions causes the creation of more $\mathrm{Ce}^{3+}$ cations in pure ceria than in Ag-modified ceria, consistent with the experimental data (Fig. 1c).

\section{- Reduction in $\mathrm{H}_{2}$ atmosphere}

In $\mathrm{H}_{2}$ environment, both hydrogen adsorption and the formation of oxygen vacancies contribute to the surface reduction. As shown by recent computational studies, the dissociative adsorption of $\mathrm{H}_{2}$ has an activation energy $E_{a}=0.99 \mathrm{eV}$ and leads to the reduction of two Ce ions on the pristine surface ${ }^{32} 31$, whereas the barrier is much lower, $0.34 \mathrm{eV}$, on $\mathrm{Ag}: \mathrm{CeO}_{2}$, where one $\mathrm{Ce}$ ion and one $\mathrm{Ag}$ are reduced ${ }^{16}$. These results suggest that the hydrogen coverage should be higher on $\mathrm{Ag}: \mathrm{CeO}_{2}$ than on the pristine surface at low temperature, whereas the fraction of $\mathrm{Ce}^{3+}$ ions should be higher on the pristine surface, a result consistent with the experimental data in Figs. $1 \mathrm{c}$ and $3 \mathrm{~b}$. These results are also compatible with the decrease of $\mathrm{Ag}$ oxidation state observed by XPS after $\mathrm{H}_{2}$ exposure at high temperature (Figure 2).

Under conditions of high temperature and low water pressure, adsorbed hydrogen $\left(\mathrm{H}_{\mathrm{ads}}\right)$ on reducible metal oxides can undergo the reaction

$$
2 \mathrm{H}_{\mathrm{ads}}+\mathrm{O}_{\mathrm{s}} \rightarrow \mathrm{H}_{2} \mathrm{O}+\mathrm{O}_{\mathrm{v}}
$$

where $\mathrm{O}_{s}$ and $\mathrm{O}_{v}$ denote a surface oxygen atom and surface oxygen vacancy, respectively. Temperature programmed reduction measurements acquired by several groups on cerium oxide powdered catalysts indicate that adsorbed hydrogen can indeed be released from the surface in the form of $\mathrm{H}_{2} \mathrm{O}$ forming $\mathrm{O}$ vacancies on the surface at around $770 \mathrm{~K}$, while the formation of bulk oxygen vacancies requires a temperature of $1100 \mathrm{~K} .{ }^{810}$

Table 1 - Relative free energies (in eV) of non-interacting gas phase $\mathrm{H}_{2}$ and surface $\left(\mathrm{H}_{2}(\mathrm{~g})+\right.$ surface), surface with adsorbed hydrogen $\left(2 \mathrm{H}_{a d s}\right)$, and reduced surface with a desorbed gas phase water molecule $\left(\mathrm{H}_{2} \mathrm{O}(\mathrm{g})+\mathrm{O}_{v}\right)$ at different temperatures. The energy of the $2 \mathrm{H}_{\text {ads }}$ state is taken as the reference. Values in bold are computed at the low pressure of the experiment $\left(p_{H 2}=10^{-10}\right.$ bar $)$, those in parentheses refer to the standard pressure $\left(p^{0}\right.$ $=1 \mathrm{bar}$ ). Reported values include zero-point energy corrections of gas phase and adsorbed species and entropic 
contributions to the free energy of gas phase molecules only. Water formation ( $\mathrm{H}_{2}$ adsorption) is much more (less) exothermic at low pressure.

\begin{tabular}{|c|c|c|c|c|c|c|}
\hline Surface Type & State & $T=0 K$ & $\mathrm{~T}=300 \mathrm{~K}$ & $T=400 \mathrm{~K}$ & $\mathrm{~T}=500 \mathrm{~K}$ & $\mathrm{~T}=600 \mathrm{~K}$ \\
\hline \multirow[t]{3}{*}{$\mathrm{CeO}_{2}$} & $\mathrm{H}_{2}(\mathrm{~g})+$ surf & 2.05 & $\begin{array}{c}1.14 \\
(1.73) \\
\end{array}$ & $\begin{array}{c}\mathbf{0 . 8 0} \\
(1.59) \\
\end{array}$ & $\begin{array}{c}\mathbf{0 . 4 6} \\
(1.44) \\
\end{array}$ & $\begin{array}{c}\mathbf{0 . 1 1} \\
(1.29) \\
\end{array}$ \\
\hline & $2 \mathrm{H}_{\text {ads }}$ & 0.00 & 0.00 & 0.00 & 0.00 & 0.00 \\
\hline & $\mathrm{H}_{2} \mathrm{O}(\mathrm{g})+\mathrm{O}_{\mathrm{v}}$ & 0.89 & $\begin{array}{c}-0.18 \\
(0.41) \\
\end{array}$ & $\begin{array}{l}-0.59 \\
(0.20) \\
\end{array}$ & $\begin{array}{c}-0.99 \\
(-0.01) \\
\end{array}$ & $\begin{array}{l}-1.40 \\
(-0.22) \\
\end{array}$ \\
\hline \multirow[t]{3}{*}{$\mathrm{Ag}: \mathrm{CeO}_{2}$} & $\mathrm{H}_{2}(\mathrm{~g})+$ surf & 2.38 & $\begin{array}{c}1.47 \\
(2.06) \\
\end{array}$ & $\begin{array}{c}1.13 \\
(1.92)\end{array}$ & $\begin{array}{c}\mathbf{0 . 7 9} \\
(1.77) \\
\end{array}$ & $\begin{array}{c}\mathbf{0 . 4 4} \\
(1.62)\end{array}$ \\
\hline & $2 \mathrm{H}_{\text {ads }}$ & 0.00 & 0.00 & 0.00 & 0.00 & 0.00 \\
\hline & $\mathrm{H}_{2} \mathrm{O}(\mathrm{g})+\mathrm{O}_{\mathrm{v}}$ & 0.75 & $\begin{array}{c}-0.32 \\
(0.27)\end{array}$ & $\begin{array}{l}-0.73 \\
(0.06)\end{array}$ & $\begin{array}{c}-1.13 \\
(-0.15)\end{array}$ & $\begin{array}{c}-1.54 \\
(-0.36)\end{array}$ \\
\hline
\end{tabular}

The computed relative free energies of the reactant and product states of (1) on the pristine and Ag-doped $\mathrm{CeO}_{2}$ surface are reported in Table 1 for several temperatures between zero and $600 \mathrm{~K}$. As expected, the adsorption of $\mathrm{H}_{2}$ becomes increasingly less exothermic with increasing temperature, while the reverse is true for the formation of a water molecule from two adsorbed $\mathrm{H}$ and a surface oxygen atom. At the low pressure of our experiment, in particular, water formation is (slightly) exothermic already at room temperature and leads to a free energy gain even larger than that of $\mathrm{H}_{2}$ adsorption above $\sim 450 \mathrm{~K}$.

As a plausible pathway for reaction (1), we assume that water formation is due to the diffusion of one $\mathrm{H}_{\text {ads }}$ to another surface $\mathrm{OH}_{\text {ads }}$ group with which it recombines. Diffusion of $\mathrm{H}$ into the bulk could be another possible pathway for the hydrogen atoms, but it would not account for the observed trends since it would lead to the reduction of the surface $\mathrm{O}-\mathrm{H}$ without changing the surface $\mathrm{O}$ content. Our calculated Minimum Energy Pathways for reaction (1) on the pristine and Ag-doped surfaces are shown in Fig. 6 . To estimate the barrier for $\mathrm{H}$ diffusion, we follow Fernández-Torre. ${ }^{30}$, who found that a $\mathrm{H}$ atom on $\mathrm{CeO}_{2}(111)$ first diffuses from $\mathrm{O}_{s}$ (Initial state IS) to a subsurface oxygen $\left(\mathrm{O}_{\text {sub }}\right.$ ), reaching a metastable state (MS). For pristine $\mathrm{CeO}_{2}$, our computed energy barrier for $\mathrm{H}$ diffusion from a surface to a subsurface oxygen (IS $\rightarrow \mathrm{MS}$ ) is $1.13 \mathrm{eV}$, while it is $0.77 \mathrm{eV}$ for $\mathrm{Ag}: \mathrm{CeO}_{2}$. The computed barrier for $\mathrm{H}_{2} \mathrm{O}$ desorption (the finale state $\mathrm{FS}$ ) is in both cases lower than the $\mathrm{H}$ diffusion barrier, indicating that $\mathrm{H}$ diffusion is the rate limiting process for water formation on both surfaces. The lower $\mathrm{H}$-diffusion barrier on the $\mathrm{Ag}: \mathrm{CeO}_{2}$ surface thus suggests that water is more likely to form on Ag-modified than on pristine $\mathrm{CeO}_{2}$.

The results of our calculations allow us to explain the observed trends in the surface concentration of $\mathrm{OH}$, shown in Figure $3 \mathrm{~b}$, which increases with the RT exposure of the film to $\mathrm{H}_{2}$, slightly decreases at $470 \mathrm{~K}$ and significantly increases above $570 \mathrm{~K}$. The increase at RT after $\mathrm{H}_{2}$ exposure is related to $\mathrm{H}_{2}$ adsorption and dissociation, which are predicted to have activation barriers of 0.99 and $0.34 \mathrm{eV}$ on the pristine and Ag-doped 
surfaces respectively, consistent with the observed larger concentration on the latter. As the temperature is increased to $470 \mathrm{~K}$, water formation and desorption become important, leading to a decrease of both surface $\mathrm{O}$ and $\mathrm{OH}$ concentrations. At higher temperature the annealing and subsequent cooling of the film in $\mathrm{H}_{2}$ induces further hydrogen dissociation and a consequent increase of the concentration of $\mathrm{OH}$ bonds. $\mathrm{H}$ preferentially binds to oxygen atoms, which have a higher concentration on the pristine ceria than on the Agmodified surface, explaining the higher $\mathrm{OH}$ concentration on the former after the treatment at high temperatures. Also the significant decrease in $\mathrm{O} / \mathrm{Ce}$ ratio shown in Figure $3 \mathrm{c}$ for the $\mathrm{Ag}: \mathrm{CeO}_{2}$ indicates a higher concentration of oxygen vacancies on the Ag-modified surface, which is likely due to a more efficient water formation on this surface, as predicted by the DFT results. Furthermore, the larger concentration of surface $\mathrm{OH}$ groups on the pristine surface than on $\mathrm{Ag}: \mathrm{CeO}_{2}$ possibly contributes to the much larger concentration of $\mathrm{Ce}^{3+}$ ions experimentally observed on pristine $\mathrm{CeO}_{2}$ than on $\mathrm{Ag}: \mathrm{CeO}_{2}$ after hydrogen exposure, reported in Fig. 1c.

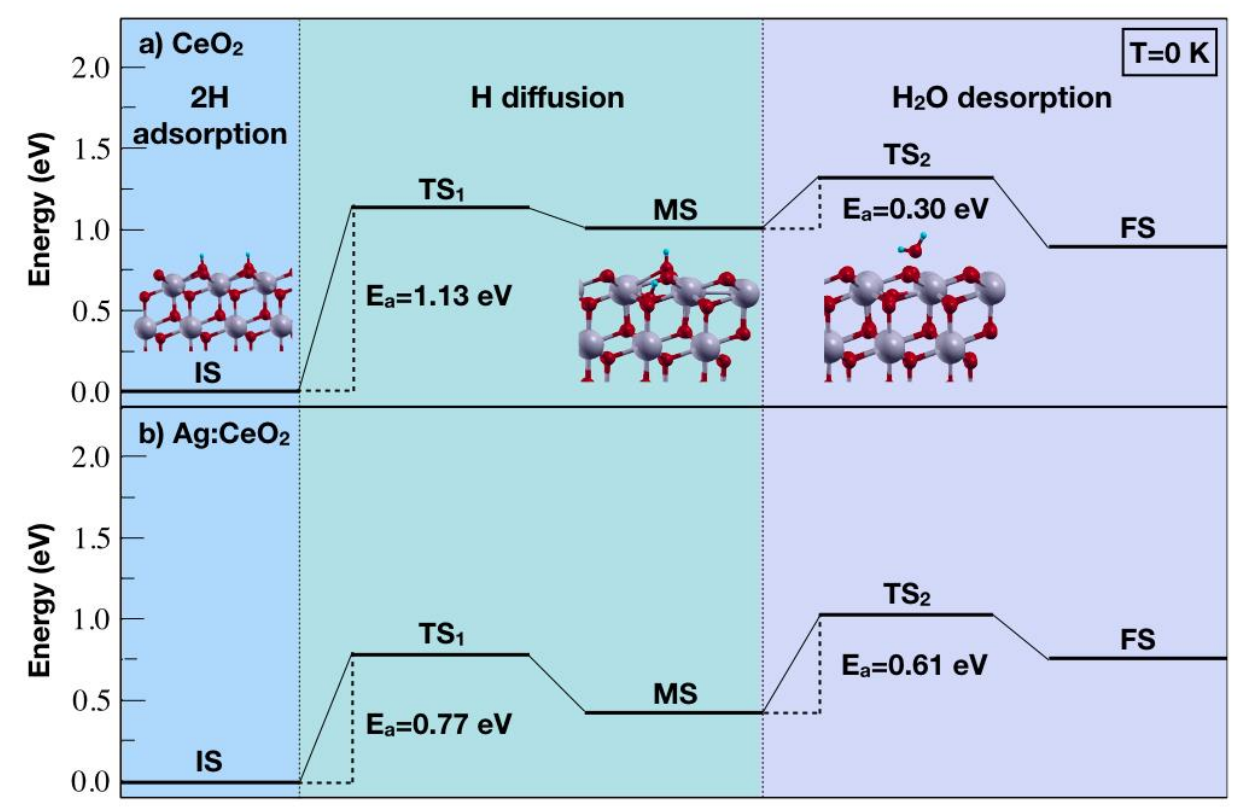

Fig. 6 Minimum Energy Path (MEP) of reaction (1) on the a) $\mathrm{CeO}_{2}$ and b) $\mathrm{Ag}: \mathrm{CeO}_{2}$ surface at $\mathrm{T}=0 \mathrm{~K}$. The energy zero corresponds to the surface with dissociatively adsorbed $\mathrm{H}_{2}$. Grey balls indicate cerium atoms, red balls oxygen atoms, and the small light blue balls the hydrogen atoms.

\section{Conclusions}

In this work we aimed to obtain insight into the reactivity of Ag-modified ceria films towards $\mathrm{H}_{2}$ by investigating the changes occurring on the film surface after thermal treatments in vacuum and in hydrogen 
partial pressure. As expected, the $\mathrm{H}_{2}$ environment induces a significantly higher $\mathrm{Ce}^{3+}$ concentration as compared to reduction in vacuum at the same temperatures. Quite surprisingly, however, the Ag-modified sample showed a lower concentration of $\mathrm{Ce}^{3+}$ cations than the pristine ceria one under all conditions, also in the presence of a greater number of oxygen vacancies. To interpret these results, we carried out DFT calculations and found that the presence of $\mathrm{Ag}$ reduces the barrier of $\mathrm{H}_{2}$ dissociation on the ceria surface, explaining the larger concentration of $\mathrm{OH}$ groups on the Ag-modified surface at low temperature, as observed experimentally. Our calculations also show that doping with $\mathrm{Ag}$ decreases the activation barrier for surface diffusion of adsorbed $\mathrm{H}$ atoms, which is the rate limiting process for water formation, thus suggesting a larger rate of water formation on the Ag-modified than on the pristine samples at high temperature. This prediction is confirmed by the higher concentration of surface oxygen vacancies and lower concentration of $\mathrm{OH}$ groups on the $\mathrm{Ag}: \mathrm{CeO}_{2}$ surface found in the experiments. Both $\mathrm{H}_{2}$ dissociative adsorption and oxygen vacancies contribute to the creation of $\mathrm{Ce}^{3+}$ cations, but in both cases the number of reduced Ce cations is predicted to be two times larger on the pristine ceria surface relative to the Ag-modified one, in agreement with the experiment.

Our analysis shows that while measuring the amount of reduced $\mathrm{Ce}^{3+}$ cations often provides a reliable estimate of the $\mathrm{CeO}_{2}$ surface activity towards oxidation reactions, this is not the case for Ag-modified $\mathrm{CeO}_{2}$. Due to the tendency of $\mathrm{Ag}$ to compete with $\mathrm{Ce}$ in the acquisition of part of the surface electrons made available by hydrogen adsorption and oxygen vacancy formation, the concentration of $\mathrm{Ce}^{3+}$ cations remains relatively low even if the surface reactivity to hydrogen is enhanced.

Altogether, these results provide new insights into the mechanism of $\mathrm{H}_{2}$ activation on $\mathrm{CeO}_{2}$-based materials that could help the development of efficient Pt-free electrode materials for electro-chemical devices.

\section{ASSOCIATED CONTENT}

\section{Supporting Information}

Figure S1: Fit of Ce 3d spectra from $\mathrm{CeO}_{2}$ film on Pt reduced at $770 \mathrm{~K}_{\text {in }} \mathrm{H}_{2}$, performed following the wellestablished procedure described by Skála, T. ${ }^{35}{ }^{36}$. The figure shows the five doublets (blue for $\mathrm{Ce}^{3+}$, light blue for $\mathrm{Ce}^{4+}$ ) and the Shirley background.

Figure S2: (a) Ce 3d and (b) $\mathrm{O} 1 \mathrm{~s}$ on pristine $\mathrm{CeO}_{2}$ annealed at $770 \mathrm{~K}_{\text {in }} \mathrm{H}_{2}$ measured at normal (red) and grazing (black) emission. The $\mathrm{Ce}^{3+}$ contribution in the $\mathrm{Ce} 3 \mathrm{~d}$ and of the $\mathrm{O}-\mathrm{H}$ contribution in the $\mathrm{O} 1$ s spectra are more intense at grazing emission, demonstrating that the investigated processes take place primarily at the surface. 
Figure S3: Ce 3d spectra for $5 \mathrm{ML}$ of pure $\mathrm{CeO}_{2}$ in (a) $\mathrm{UHV}$ and (b) $\mathrm{H}_{2}$ and $\mathrm{Ag}$-modified $\mathrm{CeO}_{2}$ (c-d) in the same environments. Red curves are the fits performed following the procedure reported by Skála, et al. ${ }^{35} 36$ as described in Figure S1.

Table S1: $\mathrm{Ce}^{3+}$ concentration obtained by the fitting procedure described in Figure $\mathrm{S} 1$ and reported in Figure 1 for the pure $\mathrm{CeO}_{2}$ and $\mathrm{Ag}$-modified films after annealing in $\mathrm{UHV}$ and $\mathrm{H}_{2}$.

Figure S4: $100 \times 100 \mathrm{~nm}^{2} \mathrm{STM}$ images of $5 \mathrm{ML}\left(1.56 \mathrm{~nm}\right.$ ) Ag-modified $\mathrm{CeO}_{2}$ film: (a) oxidized at $770 \mathrm{~K}$ in $\mathrm{O}_{2}$ and (b) annealed at $770 \mathrm{~K}$ in $\mathrm{H}_{2}(\mathrm{U}=2.5 \mathrm{~V}, \mathrm{I}=0.08 \mathrm{nA})$. Images show that the exposure to $\mathrm{H}_{2}$ at high temperature does not induce significant modifications in the film morphology.

\section{AUTHOR INFORMATION}

\section{Corresponding Author}

*E-mail: rita.magri@unimore.it

\section{Present Address:}

${ }^{\#}$ G. R.: Istituto Officina dei Materiali (IOM) c/o Scuola Internazionale Superiore di Studi Avanzati (SISSA), Via Bonomea 265, 43136 Trieste, Italy

\section{Acknowledgements}

The authors wish to thank Sergio Valeri for his support and for fruitful discussions. The work is performed with the financial support of Università degli Studi di Modena e Reggio Emilia through the FAR2016 project titled: "Innovative (oxide-based) materials and methods for fuel cell electrodes implementation". Financial support from MIUR through PRIN project no. 2015CL3APH is also acknowledged. A.S. acknowledges support from DoE-BES, Division of Chemical Sciences, Geosciences and Biosciences under Award DESC0007347. We also acknowledge use of computational resources at the TIGRESS high performance computer center at Princeton University.

\section{REFERENCES}

(1) Montini, T.; Melchionna, M.; Monai, M.; Fornasiero, P. Fundamentals and Catalytic Applications of CeO2-Based Materials. Chemical Reviews 2016, 116 (10), 5987-6041. https://doi.org/10.1021/acs.chemrev.5b00603.

(2) Trovarelli, A.; Fornasiero, P. Catalysis by Ceria and Related Materials; World Scientific, 2013; Vol. 
(3) Trovarelli, A.; Leitenburg, C. de; Boaro, M.; Dolcetti, G. The Utilization of Ceria in Industrial Catalysis. Catalysis Today 1999, 50 (2), 353-367. https://doi.org/10.1016/S0920-5861(98)00515-X.

(4) Celardo, I.; Pedersen, J. Z.; Traversa, E.; Ghibelli, L. Pharmacological Potential of Cerium Oxide Nanoparticles. Nanoscale 2011, 3 (4), 1411-1420. https://doi.org/10.1039/C0NR00875C.

(5) Fiala, R.; Figueroba, A.; Bruix, A.; Vaclavu, M.; Rednyk, A.; Khalakhan, I.; Vorokhta, M.; Lavkova, J.; Illas, F.; Potin, V.; Matolinova, I.; Neyman, K. M.; Matolin, V. High Efficiency of Pt2+- CeO2 Novel Thin Film Catalyst as Anode for Proton Exchange Membrane Fuel Cells. Applied Catalysis B: Environmental 2016, 197, 262-270. https://doi.org/10.1016/j.apcatb.2016.02.036.

(6) Fiala, R.; Vaclavu, M.; Rednyk, A.; Khalakhan, I.; Vorokhta, M.; Lavkova, J.; Potin, V.; Matolinova, I.; Matolin, V. Pt-CeOx Thin Film Catalysts for PEMFC. Catalysis Today 2015, 240, 236-241. https://doi.org/10.1016/j.cattod.2014.03.069.

(7) Lykhach, Y.; Bruix, A.; Fabris, S.; Potin, V.; Matolínová, I.; Matolín, V.; Libuda, J.; Neyman, K. M. Oxide-Based Nanomaterials for Fuel Cell Catalysis: The Interplay between Supported Single Pt Atoms and Particles. Catalysis Science \& Technology 2017, 7 (19), 4315-4345. https://doi.org/10.1039/C7CY00710H.

(8) Vilé, G.; Bridier, B.; Wichert, J.; Pérez-Ramírez, J. Ceria in Hydrogenation Catalysis: High Selectivity in the Conversion of Alkynes to Olefins. Angewandte Chemie International Edition 2012, 51 (34), 8620-8623. https://doi.org/10.1002/anie.201203675.

(9) Vilé, G.; Colussi, S.; Krumeich, F.; Trovarelli, A.; Pérez-Ramírez, J. Opposite Face Sensitivity of $\mathrm{CeO} 2$ in Hydrogenation and Oxidation Catalysis. Angewandte Chemie International Edition 2014, 53 (45), 12069-12072. https://doi.org/10.1002/anie.201406637.

(10) Aneggi, E.; Boaro, M.; Leitenburg, C. de; Dolcetti, G.; Trovarelli, A. Insights into the Redox Properties of Ceria-Based Oxides and Their Implications in Catalysis. Journal of Alloys and Compounds 2006, 408-412, 1096-1102. https://doi.org/10.1016/j.jallcom.2004.12.113.

(11) Höcker, J.; Menteş, T. O.; Sala, A.; Locatelli, A.; Schmidt, T.; Falta, J.; Senanayake, S. D.; Flege, J. I. Unraveling the Dynamic Nanoscale Reducibility (Ce4+ $\rightarrow \mathrm{Ce} 3+$ ) of $\mathrm{CeOx}-\mathrm{Ru}$ in Hydrogen Activation. Advanced Materials Interfaces 2015, 2 (18), 1500314. https://doi.org/10.1002/admi.201500314.

(12) Werner, K.; Weng, X.; Calaza, F.; Sterrer, M.; Kropp, T.; Paier, J.; Sauer, J.; Wilde, M.; Fukutani, K.; Shaikhutdinov, S.; Freund, H.-J. Toward an Understanding of Selective Alkyne Hydrogenation on Ceria: On the Impact of O Vacancies on H2 Interaction with CeO2(111). J. Am. Chem. Soc. 2017, 139 (48), 1760817616. https://doi.org/10.1021/jacs.7b10021.

(13) McFarland, E. W.; Metiu, H. Catalysis by Doped Oxides. Chemical reviews 2013, 113 (6), 43914427. https://doi.org/10.1021/cr300418s.

(14) Liu, J. Catalysis by Supported Single Metal Atoms. Acs Catalysis 2016, 7 (1), 34-59. https://doi.org/10.1021/acscatal.6b01534.

(15) Qiao, B.; Liu, J.; Wang, Y.-G.; Lin, Q.; Liu, X.; Wang, A.; Li, J.; Zhang, T.; Liu, J. Highly Efficient Catalysis of Preferential Oxidation of CO in H2-Rich Stream by Gold Single-Atom Catalysts. ACS Catalysis 2015, 5 (11), 6249-6254. https://doi.org/10.1021/acscatal.5b01114.

(16) Righi, G.; Magri, R.; Selloni, A. H2 Dissociation on Noble Metal Single Atom Catalysts Adsorbed 
on and Doped into CeO2 (111). J. Phys. Chem. C 2019, 123 (15), 9875-9883.

https://doi.org/10.1021/acs.jpcc.9b00609.

(17) Gasperi, G.; Brugnoli, L.; Pedone, A.; Menziani, M. C.; Valeri, S.; Luches, P. Reducibility of Agand $\mathrm{Cu}$-Modified Ultrathin Epitaxial Cerium Oxide Films. J. Phys. Chem. C 2019.

https://doi.org/10.1021/acs.jpcc.9b02378.

(18) Tang, Y.; Zhang, H.; Cui, L.; Ouyang, C.; Shi, S.; Tang, W.; Li, H.; Chen, L. Electronic States of Metal (Cu, Ag, Au) Atom on CeO2 (1 11 1) Surface: The Role of Local Structural Distortion. Journal of Power Sources 2012, 197, 28-37. https://doi.org/10.1016/j.jpowsour.2011.09.026.

(19) Luches, P.; Pagliuca, F.; Valeri, S. Structural and Morphological Modifications of Thermally Reduced Cerium Oxide Ultrathin Epitaxial Films on Pt(111). Phys. Chem. Chem. Phys. 2014, 16 (35), 18848-18857. https://doi.org/10.1039/C4CP02723J.

(20) Luches, P.; Pagliuca, F.; Valeri, S.; Illas, F.; Preda, G.; Pacchioni, G. Nature of Ag Islands and Nanoparticles on the CeO2(111) Surface. The Journal of Physical Chemistry C 2012, 116 (1), 1122-1132. https://doi.org/10.1021/jp210241c.

(21) Szabová, L.; Stetsovych, O.; Dvořák, F.; Farnesi Camellone, M.; Fabris, S.; Mysliveček, J.; Matolín, V. Distinct Physicochemical Properties of the First Ceria Monolayer on $\mathrm{Cu}(111)$. J. Phys. Chem. C 2012, 116 (11), 6677-6684. https://doi.org/10.1021/jp211955v.

(22) Pan, Y.; Nilius, N.; Freund, H.-J.; Paier, J.; Penschke, C.; Sauer, J. Titration of $\mathrm{Ce}^{3+}$ Ions in the CeO2(111) Surface by Au Adatoms. Phys. Rev. Lett. 2013, 111 (20), 206101.

https://doi.org/10.1103/PhysRevLett.111.206101.

(23) Brugnoli, L.; Pedone, A.; Menziani, M. C.; Adamo, C.; Labat, F. H2 Dissociation and Water Evolution on Silver-Decorated CeO2(111): A Hybrid Density Functional Theory Investigation. J. Phys. Chem. C 2019, 123 (42), 25668-25679. https://doi.org/10.1021/acs.jpcc.9b06805.

(24) Righi, G.; Anderlini, L.; Magri, R. Reduced Cerium Configurations in CeO2/Ag Inverse Catalysis. Materials Letters 2019, 126935. https://doi.org/10.1016/j.matlet.2019.126935.

(25) Ševčíková, K.; Nehasil, V.; Vorokhta, M.; Haviar, S.; Matolín, V.; Matolínová, I.; Mašek, K.; Píš, I.; Kobayashi, K.; Kobata, M.; Nagata, T.; Matsushita, Y.; Yoshikawa, H. Altering Properties of Cerium Oxide Thin Films by Rh Doping. Materials Research Bulletin 2015, 67, 5-13. https://doi.org/10.1016/j.materresbull.2015.02.059.

(26) Wang, X.; Rodriguez, J. A.; Hanson, J. C.; Gamarra, D.; Martínez-Arias, A.; Fernández-García, M. Unusual Physical and Chemical Properties of $\mathrm{Cu}$ in Ce1-XCuxO2 Oxides. J. Phys. Chem. B 2005, 109 (42), 19595-19603. https://doi.org/10.1021/jp051970h.

(27) Nolan, M. Enhanced Oxygen Vacancy Formation in Ceria (111) and (110) Surfaces Doped with Divalent Cations. J. Mater. Chem. 2011, 21 (25), 9160-9168. https://doi.org/10.1039/C1JM11238D.

(28) Hu, Z.; Li, B.; Sun, X.; Metiu, H. Chemistry of Doped Oxides: The Activation of Surface Oxygen and the Chemical Compensation Effect. J. Phys. Chem. C 2011, 115 (7), 3065-3074.

https://doi.org/10.1021/jp110333z.

(29) Shapovalov, V.; Metiu, H. Catalysis by Doped Oxides: CO Oxidation by AuxCe1- XO2. Journal of Catalysis 2007, 245 (1), 205-214. https://doi.org/10.1016/j.jcat.2006.10.009. 
(30) Fernández-Torre, D.; Carrasco, J.; Ganduglia-Pirovano, M. V.; Pérez, R. Hydrogen Activation, Diffusion, and Clustering on $\mathrm{CeO} 2$ (111): A DFT+ U Study. The Journal of chemical physics 2014, 141 (1), 14703. https://doi.org/10.1063/1.4885546.

(31) García-Melchor, M.; López, N. Homolytic Products from Heterolytic Paths in H2 Dissociation on Metal Oxides: The Example of CeO2. The Journal of Physical Chemistry C 2014, 118 (20), 10921-10926. https://doi.org/10.1021/jp502309r.

(32) Negreiros, F. R.; Camellone, M. F.; Fabris, S. Effects of Thermal Fluctuations on the Hydroxylation and Reduction of Ceria Surfaces by Molecular H2. The Journal of Physical Chemistry C 2015, 119 (37), 21567-21573.

(33) Vicario, G.; Balducci, G.; Fabris, S.; de Gironcoli, S.; Baroni, S. Interaction of Hydrogen with Cerium Oxide Surfaces: A Quantum Mechanical Computational Study. J. Phys. Chem. B 2006, 110 (39), 19380-19385. https://doi.org/10.1021/jp061375v.

(34) Lykhach, Y.; Figueroba, A.; Camellone, M. F.; Neitzel, A.; Skála, T.; Negreiros, F. R.; Vorokhta, M.; Tsud, N.; Prince, K. C.; Fabris, S.; Neyman, K. M.; Matolín, V.; Libuda, J. Reactivity of Atomically Dispersed Pt2+ Species towards H2: Model Pt-CeO2 Fuel Cell Catalyst. Phys. Chem. Chem. Phys. 2016, 18 (11), 7672-7679. https://doi.org/10.1039/C6CP00627B.

(35) Skála, T.; Šutara, F.; Prince, K. C.; Matolín, V. Cerium Oxide Stoichiometry Alteration via Sn Deposition: Influence of Temperature. Journal of Electron Spectroscopy and Related Phenomena 2009, 169 (1), 20-25. https://doi.org/10.1016/j.elspec.2008.10.003.

(36) Skála, T.; Šutara, F.; Škoda, M.; Prince, K. C.; Matolín, V. Palladium Interaction with CeO2, Sn$\mathrm{Ce}-\mathrm{O}$ and Ga-Ce-O Layers. Journal of Physics: Condensed Matter 2008, 21 (5), 055005. https://doi.org/10.1088/0953-8984/21/5/055005.

(37) Horcas, I.; Fernández, R.; Gómez-Rodríguez, J. M.; Colchero, J.; Gómez-Herrero, J.; Baro, A. M. WSXM: A Software for Scanning Probe Microscopy and a Tool for Nanotechnology. Review of Scientific Instruments 2007, 78 (1), 013705. https://doi.org/10.1063/1.2432410.

(38) Perdew, J. P.; Burke, K.; Ernzerhof, M. Generalized Gradient Approximation Made Simple [Phys. Rev. Lett. 77, 3865 (1996)]. Phys. Rev. Lett. 1997, 78 (7), 1396. https://doi.org/10.1103/PhysRevLett.78.1396.

(39) Giannozzi, P.; Baroni, S.; Bonini, N.; Calandra, M.; Car, R.; Cavazzoni, C.; Ceresoli, D.; Chiarotti, G. L.; Cococcioni, M.; Dabo, I.; Dal Corso, A.; de Gironcoli, S.; Fabris, S.; Fratesi, G.; Gebauer, R.; Gerstmann, U.; Gougoussis, C. ; Kokalj, A.; Lazzeri, M; Martin-Samos, L; Marzari, N.; Mauri, F.; Mazzarello, R.; Paolini, S; Pasquarello, A.; Paulatto, L.; Sbraccia, C.; Scandolo, S.; Sclauzero, G.; Seitsonen, A. P.; Smogunov, A.; Umari, P.; and Wentzcovitch, R. M.

. QUANTUM ESPRESSO: A Modular and Open-Source Software Project for Quantum Simulations of Materials. Journal of physics: Condensed matter 2009, 21 (39), 395502.

(40) Giannozzi, P.; Andreussi, O.; Brumme, T.; Bunau, O.; Nardelli, M. B.; Calandra, M.; Car, R.; Cavazzoni, C.; Ceresoli, D.; Cococcioni, M.; Colonna, N.; Carnimeo, I.; Corso, A. D.; de Gironcoli, S.; Delugas, P.; Jr, R. A. D.; Ferretti, A.; Floris, A.; Fratesi, G.; Fugallo, G.; Gebauer, R.; Gerstmann, U.; Giustino, F.; Gorni, T.; Jia, J.; Kawamura, M.; Ko, H.-Y.; Kokalj, A.; Küçükbenli , E.; Lazzeri, M.; Marsili, M.; Marzari, N.; Mauri, F.; Nguyen, N. L.; Nguyen, H.-V.; Otero-de-la-Roza, A.; Paulatto, L.; Poncé, S.; Rocca, D.; Sabatini, R.; Santra, B.; Schlipf, M.; Seitsonen, A. P.; Smogunov, A.; Timrov, I.; Thonhauser, T.; Umari, P.; Vast, N.; Wu, X.; Baroni, S. Advanced Capabilities for Materials Modelling with QUANTUM ESPRESSO. Journal of Physics: Condensed Matter 2017, 29 (46), 465901. 
(41) Vanderbilt, D. Soft Self-Consistent Pseudopotentials in a Generalized Eigenvalue Formalism. Phys. Rev. B 1990, 41 (11), 7892-7895. https://doi.org/10.1103/PhysRevB.41.7892.

(42) Cococcioni, M.; de Gironcoli, S. Linear Response Approach to the Calculation of the Effective Interaction Parameters in the LDA+U Method. Phys. Rev. B 2005, 71 (3), 35105. https://doi.org/10.1103/PhysRevB.71.035105.

(43) Monkhorst, H. J.; Pack, J. D. Special Points for Brillouin-Zone Integrations. Phys. Rev. B 1976, 13 (12), 5188-5192. https://doi.org/10.1103/PhysRevB.13.5188.

(44) Eyring, L. Handbook on the Physics and Chemistry of Rare Earth; North-Holland, Amsterdam, 1979; Vol. 3.

(45) Loschen, C.; Carrasco, J.; Neyman, K. M.; Illas, F. First-Principles LDA+U and GGA+U Study of Cerium Oxides: Dependence on the Effective U Parameter. Phys. Rev. B 2007, 75 (3), 035115. https://doi.org/10.1103/PhysRevB.75.035115.

(46) Graciani, J.; Márquez, A. M.; Plata, J. J.; Ortega, Y.; Hernández, N. C.; Meyer, A.; Zicovich-Wilson, C. M.; Sanz, J. Fdez. Comparative Study on the Performance of Hybrid DFT Functionals in Highly Correlated Oxides: The Case of $\mathrm{CeO} 2$ and Ce2O3. J. Chem. Theory Comput. 2011, 7 (1), 56-65. https://doi.org/10.1021/ct100430q.

(47) Xie, P.; Pu, T.; Nie, A.; Hwang, S.; Purdy, S. C.; Yu, W.; Su, D.; Miller, J. T.; Wang, C. NanoceriaSupported Single-Atom Platinum Catalysts for Direct Methane Conversion. ACS Catalysis 2018, 8 (5), 4044-4048. https://doi.org/10.1021/acscatal.8b00004.

(48) Henkelman, G.; Uberuaga, B. P.; Jónsson, H. A Climbing Image Nudged Elastic Band Method for Finding Saddle Points and Minimum Energy Paths. The Journal of chemical physics 2000, 113 (22), 99019904.

(49) Fernández-Torre, D.; Carrasco, J.; Ganduglia-Pirovano, M. V.; Pérez, R. Hydrogen Activation, Diffusion, and Clustering on CeO2 (111): A DFT+ U Study. The Journal of chemical physics 2014, 141 (1), 14703.

(50) Bader, R. F. W. Atoms in Molecules; Wiley Online Library, 1990.

(51) Naumkin, A. V.; Kraut-Vass, A.; Gaarenstroom, S. W.; Powell, C. J. NIST X-Ray Photoelectron Spectroscopy Database, Version 4.1. National Institute of Standards and Technology: Gaithersburg 2012.

(52) Gaarenstroom, S. W.; Winograd, N. Initial and Final State Effects in the ESCA Spectra of Cadmium and Silver Oxides. The Journal of Chemical Physics 1977, 67 (8), 3500-3506.

https://doi.org/10.1063/1.435347.

(53) Benedetti, S.; Nilius, N.; Valeri, S.; Tosoni, S.; Albanese, E.; Pacchioni, G. Dopant-Induced Diffusion Processes at Metal-Oxide Interfaces Studied for Iron- and Chromium-Doped MgO/Mo(001) Model Systems. J. Phys. Chem. C 2016, 120 (25), 13604-13609. https://doi.org/10.1021/acs.jpcc.6b04182.

(54) Matolín, V.; Matolínová, I.; Dvořák, F.; Johánek, V.; Mysliveček, J.; Prince, K. C.; Skála, T.; Stetsovych, O.; Tsud, N.; Václavů, M.; Šmíd, B. Water Interaction with CeO2(111)/Cu(111) Model Catalyst Surface. Catalysis Today 2012, 181 (1), 124-132. https://doi.org/10.1016/j.cattod.2011.05.032.

(55) Mullins, D. R.; Albrecht, P. M.; Chen, T.-L.; Calaza, F. C.; Biegalski, M. D.; Christen, H. M.; Overbury, S. H. Water Dissociation on $\mathrm{CeO} 2(100)$ and $\mathrm{CeO} 2(111)$ Thin Films. J. Phys. Chem. C 2012, 116 
(36), 19419-19428. https://doi.org/10.1021/jp306444h.

(56) Chen, B.; Ma, Y.; Ding, L.; Xu, L.; Wu, Z.; Yuan, Q.; Huang, W. Reactivity of Hydroxyls and Water on a CeO2(111) Thin Film Surface: The Role of Oxygen Vacancy. J. Phys. Chem. C 2013, 117 (11), 58005810. https://doi.org/10.1021/jp312406f.

(57) Ganduglia-Pirovano, M. V.; Da Silva, J. L. F.; Sauer, J. Density-Functional Calculations of the Structure of near-Surface Oxygen Vacancies and Electron Localization on $\mathrm{CeO} 2$ (111). Physical review letters 2009, 102 (2), 26101.

(58) Fabris, S.; Vicario, G.; Balducci, G.; de Gironcoli, S.; Baroni, S. Electronic and Atomistic Structures of Clean and Reduced Ceria Surfaces. The Journal of Physical Chemistry B 2005, 109 (48), 22860-22867.

(59) McFarland, E. W.; Metiu, H. Catalysis by Doped Oxides. Chemical reviews 2013, 113 (6), 43914427. 


\section{TOC}
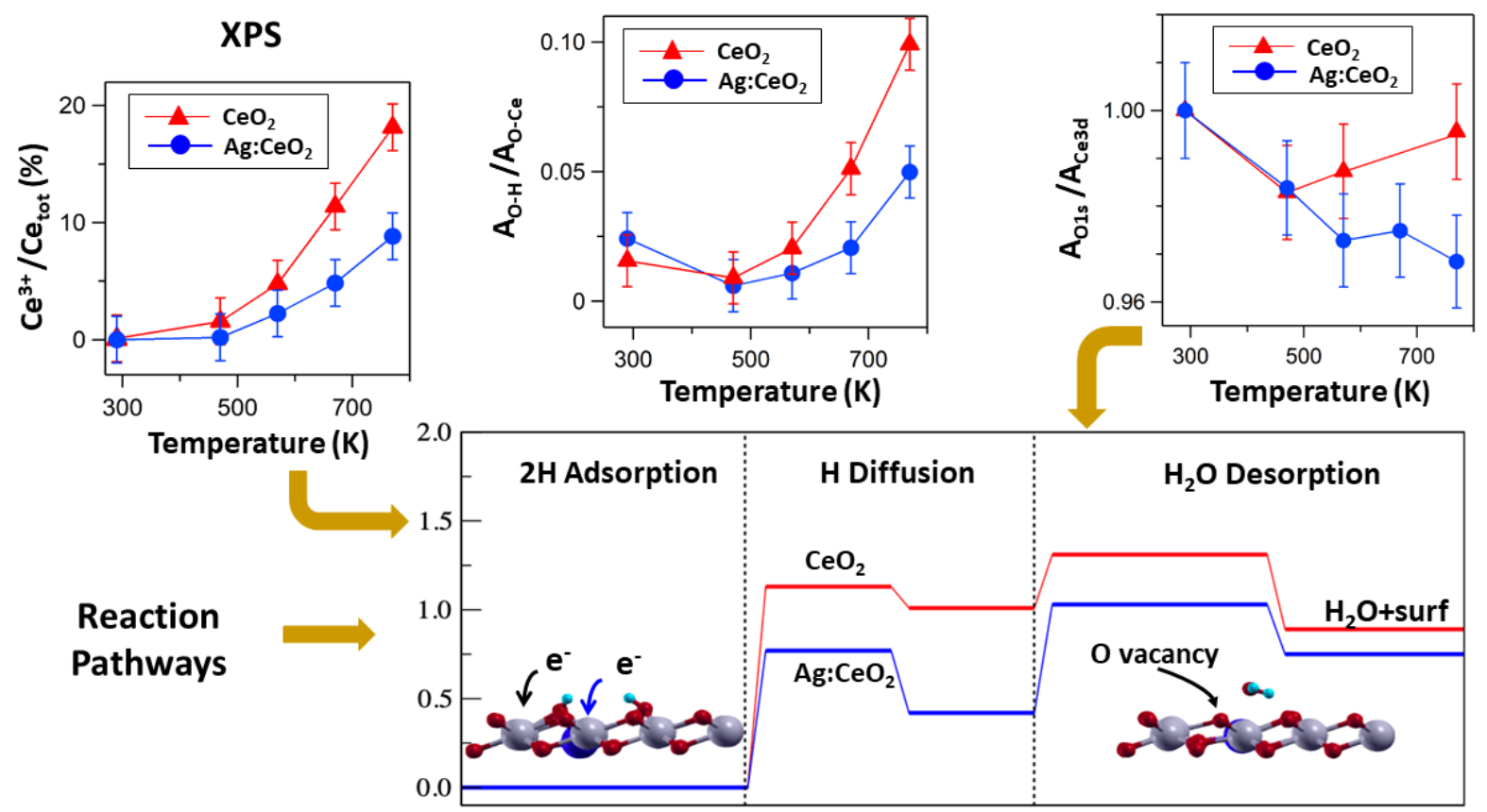